\title{
Dilatation of the Ductus Arteriosus by Prostaglandins and Prostaglandin's Precursors
}

\author{
KAZU() MOMMA." SHIGERU ULMURA. SHIGETAKE NISHHARA. AND YACHIO OTA
}

Division of Pediatric (ardiologi. The Heart Instiute of Japan. Tokvo Women's Medical College. Tokvo. Japan

\begin{abstract}
Summary
We studied the effects of prostaglandins and their precursors in animal models. Rabbit ductus arteriosus constricted rapidly after delivery. $P\left(; E_{1}, P\left(; E_{2}\right.\right.$, and arachidonic acid injected $S C$ dilated the ductus over 60 min. Orogastrically administered $P\left(; E_{2}\right.$ dilated the ductus for $3 \mathrm{hr}$. $P\left(\mathrm{GF}_{2,}\right.$ and arachidonic acid showed weak ductus-dilating effects. Response of the ductus to $P\left(\mathrm{BF}_{1}\right.$ was most prominent in the first hr after birth. Pretreatment with indomethacin blocked the ductus-dilating effect of arachidonic acid.

\section{Speculation}

Ductus-dilating effect of SC injected arachidonic acid present further support for the presumed role of the prostaglandins in maintenance of patency of the ductus arteriosus in infants with prematurity or severe congenital heart disease.

The mechanism of age-related responsiveness of the ductus arteriosus to $P\left(i F_{1}\right.$ and can be studied in animal model, and this approach may provide additional understanding and suggest new methods of management of the ductus arteriosus which is unresponsive to current medical manipulation.
\end{abstract}

Prostaglandins $E_{1}$ and $E_{2}$ ( $P\left(E_{1}\right.$ and $P\left(i E_{2}\right)$ actively dilate the constricled ductus arternosus of letal and neonatat anmats 11.4. 17. 2().21) and have been successfully used in emergency treatment of neonates with severe congenital heart disease in whom patency of the ductus arteriosus is necessary for maintenance of life $(6,9$ 12. 14. 15). Many aspects of the relationship between ductal patency and prostaglandins remain unsolved. Ductus-dilating effect of $S$ S or PO administered prostaglandins needs further evaluation. Prostaglandin's precursors such as arachidonic acid and linoleic acid remains to be studied for ductus-dilating effect. Age relationship of ductus-dilating effect of prostaglandins was noticed clinically. To shed further light on these problems. we studied the effect of prostaglandins and their precursors in animal models.

\section{MATERIALS ANI) METHODS}

We examined the effects of $P\left(j E_{1}\right.$. PGE. prostaglandin $F_{2 .}$ $(P(; F, \ldots)$ and the precursors-arachidonic acid and linoleic acid. on ductal patency in newborn rabbits. $P\left(\mathrm{~F}_{1} . \mathrm{P}\left(\mathrm{il}\right.\right.$. and $\mathrm{PC} ; \mathrm{F}_{2 .}$ were prepared for $S($ administration by dissolving in saline within 30 min prior to use. Arachidonic acid (25) was dissolved in 0.1 mole sodium carbonate in ( $\mathrm{O}$, gas in the dark within 10 min of use Linoleic acid (contained in corn oil consisting of $50 \%$; linoleic acid) (26) was injected SC. PGE, was dissolved in distilled water for PO administration.

Pregnant Japanese white rabbits obtained from a commercial supplier were sacrificed by cervical dislocation on the 30 th day of gestation. Rabbit pups were delivered by rapid caesarean section and maintained in an incubator at $37^{\circ} \mathrm{C}$ until sacrificed.

The duration of effect of prostaglandins was assessed by injecting $\mathrm{PC} ; \mathrm{E}_{1}(1 \mu \mathrm{g} / \mathrm{g}) . \mathrm{PGE}(1 \mu \mathrm{g} / \mathrm{g})$, or arachidonic acid $\left.(30) \mu \mathrm{g} / \mathrm{g}\right)$ in $0.1 \mathrm{ml}$ volume into the dorsum of the thorax in 73 pups. To compare the duration of effect of $\mathrm{PO}$ and parenteral administra- tion of prostaglandins. $P G E_{2}(2 \mu \mathrm{g} / \mathrm{g})$. was introduced through an orogastric tube into the stomach of 22 rabbits at $60 \mathrm{~min}$ after delivery. In each group, the animals were sacrificed at 15, 30. 60, and 120 min after injection. In the arachidonic acid and oral $P G E$ : groups, animals were studied $180 \mathrm{~min}$ after administration in addition.

The ductus-dilating effect of prostaglandins and precursors were studied by administering these to newborn rabbits $60 \mathrm{~min}$ after birth and sacrificing the animals $30 \mathrm{~min}$ later. Groups of rabbits. consisting of 3 to 16 in each group. were given $\mathrm{SC}^{\mathrm{PGE}} \mathrm{E}_{1}(0.0)$ to $1 \mu \mathrm{g} / \mathrm{g})$. SC PGE $2(0.001$ to $1 \mu \mathrm{g} / \mathrm{g})$, orogastric $\mathrm{PGE}_{2}(0.1$ to 10 $\mu \mathrm{g} / \mathrm{g})$. SC PGF $\mu \mathrm{g} / \mathrm{g}$ ). and $\mathrm{SC}$ linoleic acid (I to $10 \mathrm{mg} / \mathrm{g}$, given as corn oil).

The ability of indomethacin to block the ductus-dilating effects of prostaglandins was examined by comparion of two groups of rabbits, one pretretaed with indomethacin $(10 \mathrm{mg} / \mathrm{g})(31)$ injected SC $5 \mathrm{~min}$ postbirth and another without pretreatment. Arachidonic acid $(300 \mu \mathrm{g} / \mathrm{g}$ ) was administered to both groups $60 \mathrm{~min}$ after birth. and all rabbits of both groups were sacrificed $30 \mathrm{~min}$ later.

The effect of postnatal age on ductus-dilating effect of $P\left(j E_{1}\right.$ was examined by injecting $\mathrm{PGE}_{1} \mathrm{SC}^{\circ}(0.5 \mu \mathrm{g} / \mathrm{g})$ into 30 newborn rabbits at $5 \mathrm{~min}$ and $1,6.12$ and $24 \mathrm{hr}$ postbirth. Each animal was sacrificed $30 \mathrm{~min}$ after injection.

Pups were assessed for changing color, respiratery patlern, and general activity. Only active animals with regular respiratory movement and no cyanosis were included in this study. In a separate study to determine the possible effects of prostaglandins and their precursors on arterial oxygenation. blood was obtained from the carotid artery of newborn rabbits $30 \mathrm{~min}$ after $\mathrm{SC}$ injection of $\mathrm{PGE}_{1}(1 \mu \mathrm{g} / \mathrm{g})$. $\mathrm{PGE}_{2}(1 \mu \mathrm{g} / \mathrm{g}) . \mathrm{PGF}_{2,1}(10 \mu \mathrm{g} / \mathrm{g})$. or arachidonic acid $(30 \mu \mathrm{g} / \mathrm{g})$. $\mathrm{pO}, \mathrm{pCO}, \mathrm{pH}$, and base excess were measured with a Radiometer ABLl (24).

Whole-body freezing techniques $(8,17)$ were used to determine ductal diameter. Fach animal was sacrificed and fixed by immersing into acetone cooled to $-80^{\circ} \mathrm{C}$ with dry ice. The frozen chest was trimmed to obtain a sectioning surface perpendicular to the ductus arteriosus. The ductus was sectioned at $100 \mu \mathrm{m}$ from the pulmonary arterial end to the aortic end with a freezing microtome (27). The inner diameter of the ascending aorta, main pulmonary artery, and ductus arteriosus were measured with a binocular stereoscopic microscope (28) with a micrometer (29) in a frozen state without staining. The narrowest inner diameter of the ductus arteriosus was divided by the inner diameter of the main pulmonary artery to obtain a ductus arteriosus to pulmonary artery inner diameter ratio (DA/PA ratio).

For comparison with the study groups, the normal sequence of ductal closure in the untreated newborn rabbit was studied by sacrificing 54 newborn rabbits with the rapid freezing technique 0. $15,30,60$. and $90 \mathrm{~min}$ after delivery.

\section{RISULTS}

At delivery. the ductus was fully dilated and the DA/PA ratio was $1.09 \pm 0.05$ (mean \pm S.E.) (Fig. I). Rabbit ductus constricted rapidly after delivery. and $D A / P A$ ratio decreased to $0.09 \pm 0.02$ 


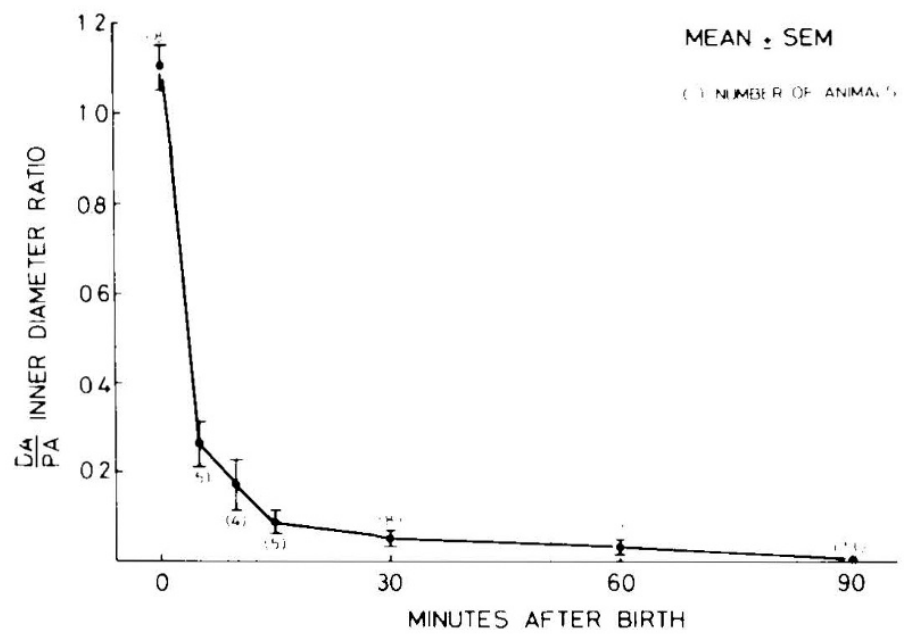

Fig. 1. Ductus closure rate in newborn rabhits. Points and hars, mean $\pm S . \mathrm{s}$

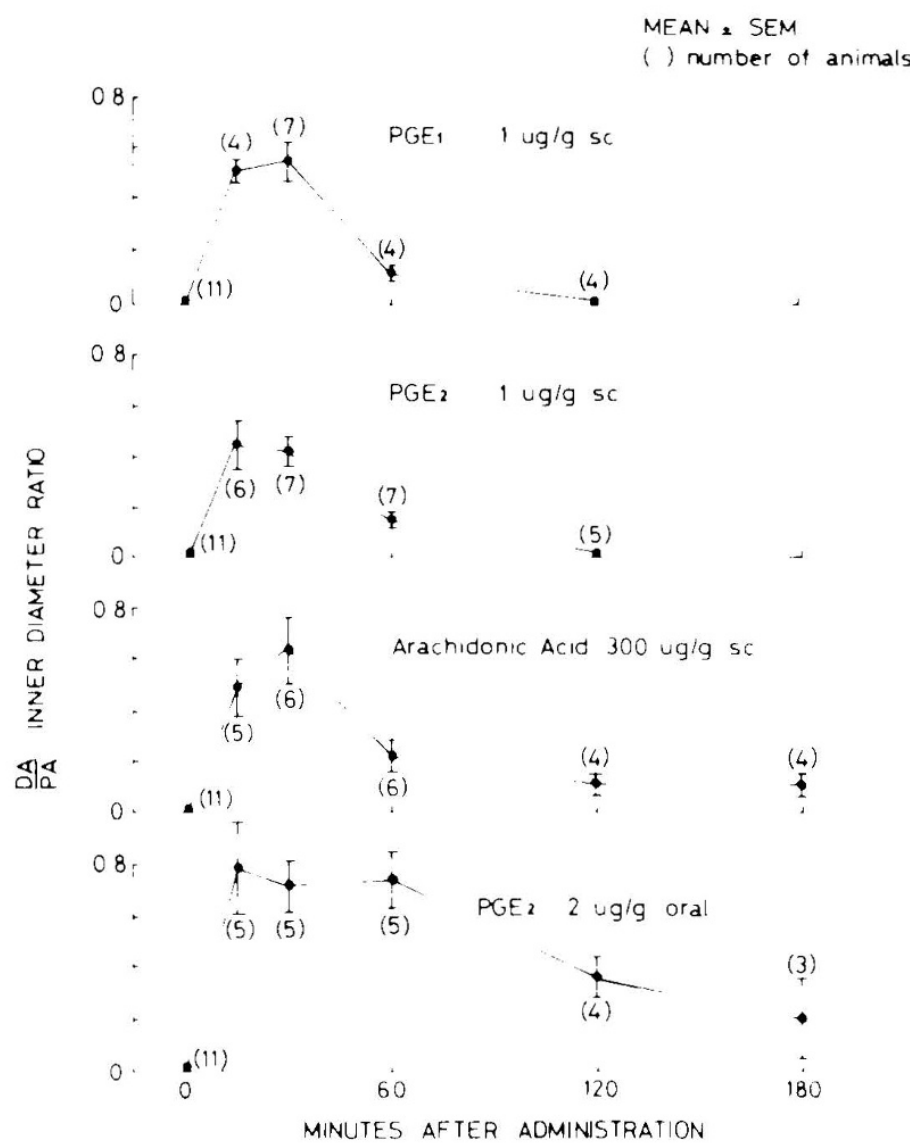

1.ig. 2. Duration of ductus-dilating effects of SC injected P( $i L_{-1}(1 \mu \mathrm{g} /$

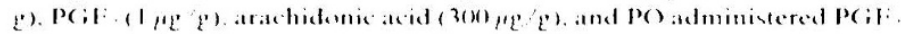
$12 / \mathrm{g} / \mathrm{g})$. Comments as for ligure 1 .

15 min after delivery. By 90 min after delivery, the ductus arteriosus of each rabbit was completely closed.

$P\left(\mathrm{FE}_{1}\right.$ and $\mathrm{PC} \mathrm{FE}_{2}$ injected $\mathrm{SC}$ dilated the ductus arteriosus over 30 min (Fig 2), and the effect largely subsided in $60 \mathrm{~min}$. Arachidonic acid injected $S C^{\circ}$ also dilated the ductus arteriosus over 30 min, and small effect persisted over $180 \mathrm{~min}$ (1.ig. 2). Orogastrically administered $P\left(\mathrm{GE}_{2}\right.$ dilated the ductus, and the maximal effect appeared in $15 \mathrm{~min}$. persisted for $1 \mathrm{hr}$, and was diminished by $3 \mathrm{hr}$ after administration. All animals discharged loose stools following nasogastric administration of $\mathrm{P}\left(\mathrm{jl}_{2}\right.$. (ieneral $s \mathrm{k}$ in color and respiratory pattern did not change following administration of either $\mathrm{PC} \mathrm{jL}_{1}$ or $\mathrm{PC} \mathrm{FE}_{2}$.

$P F_{1}$ and $P G F_{2}$ injected $S($ dilated the ductus arteriosus to the

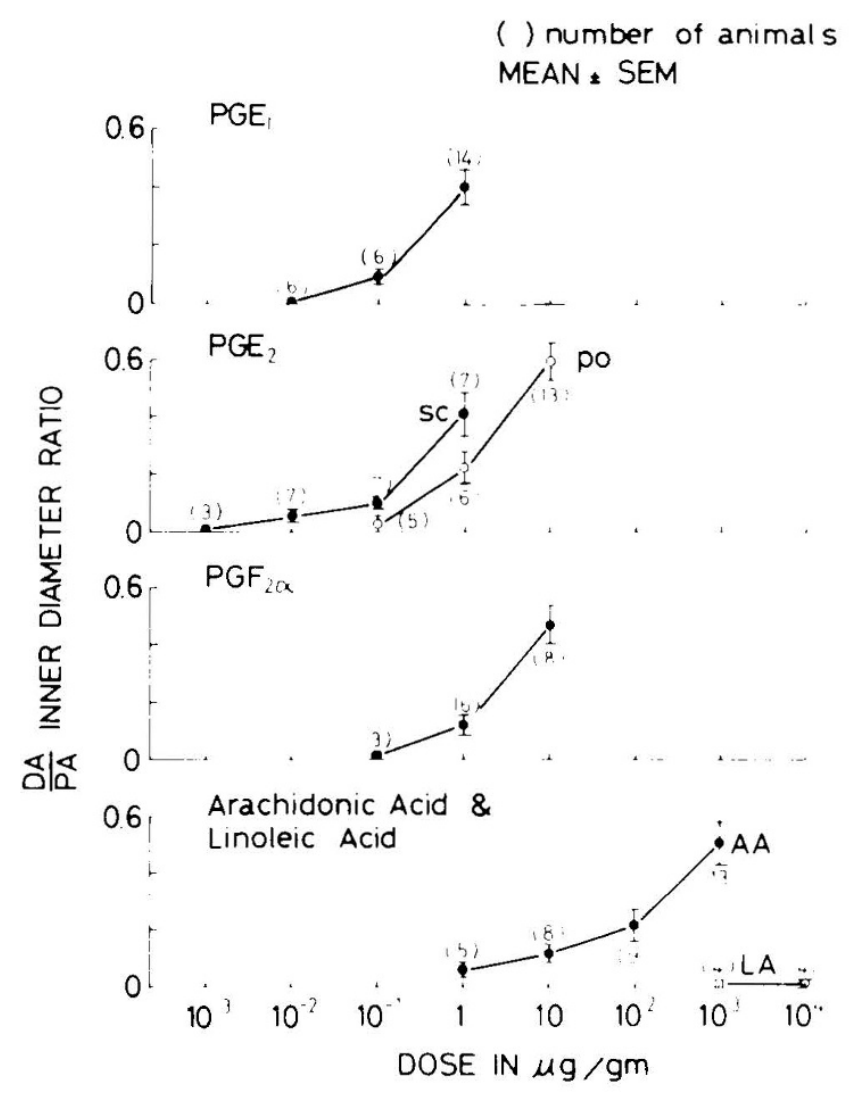

I.ig. 3. Ductus-dilating effects of $S($ injected P(iL). P(iL, P(il _... arachidonic acid (A.A), and linoleic acid $(l . A)$, and PO administered P(iL: in newborn rabbits. (omments as for ligure 1.
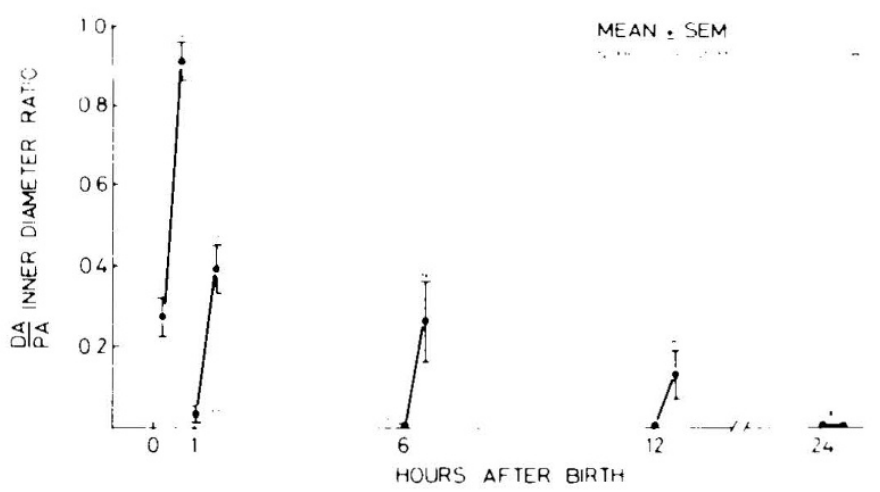

1.ig. 4. Ductus-dilating effects of $\mathrm{S}\left({ }^{\circ}\right.$ injected $\mathrm{P}(\mathrm{il}, \mathrm{l}(0) .5 \mathrm{~g} / \mathrm{g})$ in newhorn rabbits of different ages. (omments as for Figure 1 .

same degree. Orogastrically administered P(iE showed less prominent ductal dilatation than $\mathrm{SC}$ injected $\mathrm{PGE} . \mathrm{PGF}_{2,}$ and arachidomic acid showed weak ductus dilatung eflects, whereas linolete acid caused no dilatation of the ductus (Fig. 3).

The response of the ductus to $P\left(j E_{1}\right.$ was most prominent in the first hr after birth and decreased progressively for the following $24 \mathrm{hr}$ (Fig. 4). The ductus-dilating effect of S( injected arachidonic acid was effectively blocked by pretreatment with indomethacin (Table 1). No significant difference was observed in arterial pO. $\mathrm{pCO}, \mathrm{pH}$. or base excess obtained in animals administered with prestaglandins and prostaglandin precursors. as compared with a controlled group of rabbits who did not receive injections, except significantly high $\mathrm{pH}$ and low $\mathrm{pCO}_{2}$ in $\mathrm{P(iF}$. group (Table 2).

\section{I)IS( USSION}

The transformation of exogenous arachidonic acid to prostaglandins, both in vive and in vitro, has been established (16, 22). 
Table 1. Ductus-dilating effects of arachidonic acid in new born rabbits without pretreatment and in those pretreated with indomethacin

Therapeutic intervention

No treatment

Sodium carbonate

Indomethacin

Sodium carbonate and indomethacin

Arachidonic acid

Indomethacin and arachidonic acid

${ }^{1}$ Mean \pm S.E.

Our study showed that SC injected arachidonic acid dilated the closig ductus arteriosus. and this effect occurred through transformation to prostaglandins because this effect could be blocked by indomethacin (22). This is of interest when considering the mechanism of delayed closure of the ductus arteriosus associated with prematurity or other severe congenital heart disease. It has been reported that in premature infants with respiratory distress syndrome, patent ductus arteriosus, and congestive heart failure, the plasma concentration of prostaglandin $\mathrm{E}$ was initially elevated and then decreased following surgical ligation of the ductus (11). Therapeutic effectiveness of indomethacin to induce closure of the ductus arteriosus in premature infants has been established $(5,7)$. Our results are compatible with the hypothesis that increased prostaglandin formation plays a major role in persistent patency of the ductus arteriosus in the premature infants. Prostaglandins may play a similar role in delayed closure of the ductus arteriosus associated with severe congenital heart disease such as hypoplastic left heart syndrome or anomalies of aortic arch. Plasma levels of PGE: and ductal tissue levels of prostaglandin $I_{2}$ should be studied in these diseases to clarify this problem. From a therapeutic point of view, arachidonic acid has no advantage over $\mathrm{PGE}_{1}$ or $\mathrm{PGE}_{2}$ because of its unstable nature and posible fatal reaction following intravenous injection (19).

The present study revealed age dependency of the ductal response to $\mathrm{PGE}_{1}$ in the newborn rabbit. Even the constricted ductus dilated in response to $P G E_{1}$ at 6 or $12 \mathrm{hr}$ after birth, but this response disappeared by $24 \mathrm{hr}$. The counterpart of this animal experiment is found in clinical reports. Lewis et al. (10) reported that nine newborn infants, aged one to 7 days, responded to $P G E_{1}$ with dilatation of the ductus arteriosus. In two infants aged 10 and 14 days. the ductus arteriosus was completely closed and failed to respond to $P G E_{1}$, whereas a 12 th infant who did not respond was 9 wk old. Neutze et al. (14) reported ten out of 11 infants responded to administration of $\mathrm{PGE}_{1}$ or $\mathrm{PGE}_{2}$. Nine of the 10 responders were less than 10 days of age, whereas the tenth was 25 days old. The infant who did not respond was 99 days of age. Conversely. Lewis et al. (9) reported a premature infant in whom the ductus arteriosus was maintained patent by infusion of $\mathrm{PGE}_{1}$ for 29 days. Our clinical observations (12) on 15 cyanotic infants (ages one day to 8 months) with decreased pulmonary blood flow and patent ductus arteriosus showed the ductal re. sponse to $\mathrm{PGE}_{1}$ was greatest in the first 10 days after birth, decreased over the succeeding 2 months, and usually disappeared in those infants over the age of 2 months. The mechanism of this changing responsiveness with advancing age is not clear, but may be explained on the basis of structural changes in the ductal wall. such as reorganization of intimal cells and fibrosis of medial tissue.
Our present study furnishes fundamental data on the efficacy of $S C_{\text {injected }} \mathrm{PGE}_{1}$ and $P \mathrm{PG}_{2}$, as well as $\mathrm{PO}$ administered $\mathrm{PGE}$. $\mathrm{PGE}_{2}, \mathrm{PO}$ is presently uterized in certain clinical obstetrical situations (13). In newborn infants. $\mathrm{PGE}_{1}$ or $\mathrm{PGE}_{2}$ is optimally administered by continuous intravascular injection to induce dilatation of the ductus arteriosus. Recently. PO PGE: was applied clinically to maintain patency of the ductus arteriosus in neonates whose pulmonary circulation was ductus dependent (18). The PO route for administration of prostaglandins could be utilized more safely if prostaglandin derivatives could be synthesized which have potent ductus-dilating effect and little or no gastrointestinal irritation.

Clyman et al. (2) compared potency of several prostaglandins and their derivatives to dilate the ductal strip of the fetal lamb in vitro. Minor differences exist between their results and present data. They noticed significantly more potent ductus-dilating effects with $\mathrm{PGE}_{1}$ than $\mathrm{PGE}_{2}$. Species difference or difference in in vivo and in vitro conditions may explain the different results. They observed weak ductal constriction with $\mathrm{PGF}_{2,}$ with similar findings in in vitro studies (4.22). In contrast. Sharp et al. (17) observed ductus dilatation with $\mathrm{PGF}_{2,}$ in neonatal rats. findings confirmed in our study. A metabolite of PGF.. was reported to dilate the ductus arteriosus (2). This may explain the ductus-dilating effect of $\mathrm{PGF}_{2,2}$ in in vivo studies.

\section{CONCLUSION}

The ductus-dilating effect of prostaglandins and their precursors was studied in newborn rabbits. Ductal size was measured using rapid whole-body feezing technique. Injection $S C$ of $P G_{1}, P G E_{2}$. and arachidonic acid dilated the ductus arteriosus for $60 \mathrm{~min}$. Orogastric administration of PGE: dilated the ductus arteriosus for $3 \mathrm{hr}$. The potency of the ductus-dilating effect of prostaglandins followed the following order: $\mathrm{PGE} \mathrm{E}_{1}, \mathrm{PGE}, \mathrm{SC}>\mathrm{PGE}, \mathrm{PO}>$ $\mathrm{PGF}_{2,} \mathrm{SC}>$ arachidonic acid SC. Ductus-dilating effect of arachidonic acid was lost in animals pretreated with indomethacin. Ductal response to $\mathrm{PGE}_{1}$ was most prominent in the first hr after birth and subsided in the next $24 \mathrm{hr}$.

\section{RLILRLN(ISS ANI) N(IILS}

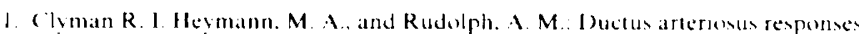
to prostaglandin $E_{1}$ at high and low oxygen concentrations. Prowtaglandins. 13: $214(1977)$

2. Clyman. R. I. Wong. L.. Heyman. M. A. and Rudolph. A M : Reoponsiveness of the lamb ductus arteriosus lo prostaglandins and ther metabolites. Prostaglandins. $15: 325(147 x)$.

3. Ciceans. I.. Bodach. E.. Whate. ... Bishat. L. and Olles. P. M Prostaglanden I is less relaxant than prostaglandin $\mathbf{L}$, on the lamb ductus arternoms. Prostaglandins. $15: 551,19781$.

4. (occani. t. and Olley, P. M: The response of the ductus ateriosus w prostaglandins. (an. J. Physiol. Pharmacol. 5/: 221$)(1973)$

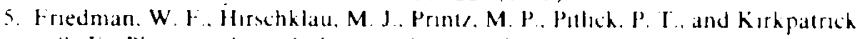
S. E.: Pharmacological closure of patent ductus arteriosus in the premature intant. N. tengl. J Med.. 205.526(1476)

f. Hevmann. M. A. and Rudolph. A. M. Ductus artercosus dilatatuen by prostaglandin $\mathrm{F}_{1}$ in infants with pulmonary atresia. Pediatrics $54: 325(1977)$

7. Heymann. M. A. Rudolph. A. M.. and Silverman. M. H ( losure of the ductus arteriosus in premature infants ho inhibition of prostaglandin sunthesis. $N$. lingl. J. Med.. 205: 530(1976).

8. Hornblad. P. Y.. and larson. K. S. Studies on closure of the ductus arterionus. 1. Whole-hody freesing as improvement of tixaton procedures. (ardologia. $51: 231(1967)$

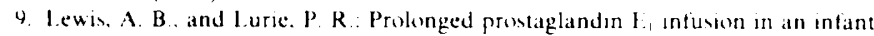
with cyanotic congenital heart disease. Pediatrics. $01: 534$ (197x).

Table 2. Arterial blood gas and $\mathrm{pH}$ of newborn rabbits 30 min after $S C$ injection of prostaglandins and arachidonic acid

\begin{tabular}{|c|c|c|}
\hline Therapeutic intervention & No. & $\underset{(\mathrm{m} m \mathrm{~m})}{\mathrm{pO})}$ \\
\hline Notreatment & 12 & $62.1 \pm 7.4$ \\
\hline$P G_{1}$ & 8 & $67.6 \pm 5.9$ \\
\hline$P\left(i E_{2}\right.$ & 5 & $66.6 \pm 9.4$ \\
\hline$P\left(j F_{2,1}\right.$ & 5 & $60.8 \pm 8.9$ \\
\hline Arachidonic acid & 7 & $77.3 \pm 7.1$ \\
\hline Indomethacin and arachidonic acid & 3 & $57.3 \pm 2.9$ \\
\hline
\end{tabular}

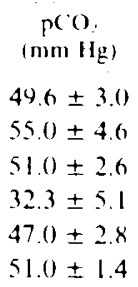

${ }^{1}$ Mean \pm S.E. 
10. Lewis. A. B., Takahashi. M.. and Lurie. P. R.: Administration of prostaglandin $E_{1}$ in neonates with critical congenital cardiac defects. J. Pediatr. "Y. 81 ( $\left.197 x\right)$

II. Manchandia, M. R., Michelakis. A. M., Karna. P., and Dolanski. E. A.: Plasma prostaglandin $E$ and $F_{2 . .}$ in premature infants with patent ductus arteriosus. Pediatr. Res., 12: 387 (1978)

12. Momma. K., and Takao, A.: Medical manipulation of the neonatal ductus arteriosus. Shinseigi domyakukan no y akusigakuteki sosa. Naika, 42: 638 (1978).

13. Nelson, (j. H., and Bryans, (. I.. Jr.: Induction of labor with oral prostaglandin $E$, in normal and high-risk pregnancies. Am. J. Obstet. (jynecol., /32: 64? (1978).

14. Neutze. J. M.. Starling, M. B., Elliott. R. B.. and Barratt-Boyes. B. G.. Palliation of cyanotic congenital heart disease in infancy with E-type prostaglandins. Circulation, 55: 238 (1977)

15. Olley, P. M., Coceani, F., and Bodach. F.: F-type prostaglandins. A new type emergency therapy for certain cyanotic heart malformations. (irculation. 5.3: $724(1976)$.

16. Rose. J. C.. Johnson. M.. Ramwell. P. W.. and Kot. P. A.: Effects of arachidonic acid on systemic arterial pressure. myocardial contractility and platelets in the dog. Proc. Soc. Exp. Biol. Med., 147: 652 (1974).

17. Sharpe. G. L.., and l arsson, K. S.: Studies on closure of the ductus arteriosus. $X$. In vivo effect of prostaglandin. Prostaglandins. 1): 703 (1975)

IX. Silove, E. D., (ive, J. Y.. Page, A. J. F.. and Mitchell, M. D).: Long term oral prostaglandin $F_{2}$ maintains patency of ductus arteriosus. Circulation Suppl. 2. 59 and 60$): 6(1979)$.

19. Silver. M. J., Hoch. W., Kocsis. J. J.. Ingerman. (. M.. and Smith. J. B.: Arachidonic acid causes sudden death in rabbits. Science (Wash. D. ( .). 183: $1085(1974)$.

20. Starling. M. B., and Elliott, R. B.: The effect of prostaglandins, prostaglandin inhibitors, and oxygen on closure of the ductus arteriosus, pulmonary arteries and umbilical vessels in virro. Prostaglandins. 11 : 187 (1974).

21. Starling. M. B., Neutze, J. M.. Eliott. R. L.. and Elliott, R. B.: Studies on the effects of prostaglandin $E_{1}, E_{2}, A_{1}$, and $A_{2}$ on the ductus arteriosus of swine in vivo using cineangiography. Prostaglandins. /2: 355 (1976).

22. Vane, J. R.: Inhibitors of prostaglandin, prostacvelin, and thromboxane synthess In: F. Coceani. P. M. Olley: Advances in Prostaglandin and Thromboxane Research. Vol. 4. p. 27 (Raven Press, Neu York, 197x).

23. Presented in part at the Eight World (ongress of (ardiology. Tokyo. Japan. September 18. 1978

24. ABLI. Radiometer, (openhagen. Denmark.

25. Arachidonic acid. grade 1. approximately 44\%, Sigma (hemical (o.. St. Louis. MO

26. Corn salad oil. Ajinomoto Fond (a.. Tokso. Japan

27. Freezing Microtome. Komatsu Solidate (io. l.td.. Tokro. Japan.

28. Nikon Binocular Stereoscopic Micrometer. Nihon-kogahu (o.. Tokyo, Japan

29. Nikon Ocular Micrometer. Nihon-Kogaku (o.. Tokvo. Japan.

30. Prostaglandins in this study were generously supplied by Ono Pharmaceutical (o.. Osaka. Japan in the following forms: P(ib, (O)o (; 511 ), sternle crystalline in ampule: $P(; 1),(O)$ no $(; 512)$, sterile cristaline in ampule. for $S($ injection: PCF.. Prostalmon $E$ in capsule that is white powder. consists of P(if., as an inclusion compound of heta-cyclo-dextrin. and is used in this study in suspension with water for orogastric administration: P(; $F_{\ldots} .$. Prostalmon $F$. sterile ayuerus solution in ampule.

31. Lyophilized indomethacin (25 mg/vial) was generously supplied by Merck Frosst Research Laboratories. Montreal. Canada.

32. Editorial help of Drs. I. M. I.inde. Clinical Professor of Pediatric Cardology. University of ( ahfornia. Lon Angeles, and T. A. Riemenschneider. Professor of ( ardiovascular Pediatrics. University of ( alifornia. Davis, is highly appre clated.

33. Requests for reprints should he addressed (o: Kazuo Momma. M. D., Division of Pediatric (ardiology. The Heart Institute of Japan. Tokyo Women's Medical (ollege, Kawadacho-j0, Shinjuku-ku. Tokyo, Japan.

34. This research was supported by Japan Research Promotion Society for Cardasvascular Diseases.

35. Received for publication June 8.1979.

36. Accepted for publication January 7. 1980. 